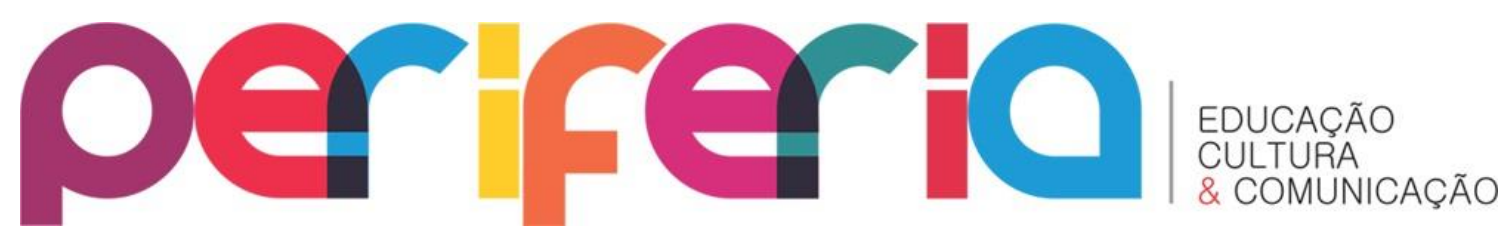

DOI: $10.12957 /$ periferia.2019.36440

\title{
A CONSTRUÇÃO DE MEMES COMO FERRAMENTA DE ENSINO DA LÍNGUA INGLESA
}

\author{
Alexandre Delfino Xavier ${ }^{1}$ \\ Instituto Federal de Minas Gerais - Ouro Preto \\ Evandro Luis Moreira de Souza ${ }^{2}$ \\ Universidade Federal de Ouro Preto \\ Shirlene Bemfica de Oliveira ${ }^{3}$ \\ Instituto Federal de Minas Gerais - Ouro Preto
}

\section{Resumo}

O advento da globalização e da multiplicidade de canais, meios ou modos semióticos de comunicação criados a partir de novas tecnologias e mídias sociais impulsionaram mudanças no contexto escolar que necessariamente passam a considerar a crescente diversidade linguística e cultural presente mundialmente (COPE, KALANTZIS, 2000). O objetivo deste artigo é apresentar e discutir uma sequência didática de ensino de língua inglesa por meio da análise, construção e compartilhamento de memes online. 0 aporte teórico é pautado nas Teorias Funcionais da Linguística Aplicada, com especial enfoque nas teorias de letramento que constituem o interacionismo. 0 estudo analítico de memes é discutido com base em questões estruturais, semânticas e críticas, a fim de propiciar a valorização da produção autoral dos memes. A partir dessa perspectiva de análise semiótica, da criatividade, do dinamismo, da inovação, do interesse e da motivação os resultados apontam para a representação e recontextualização das realidades de forma eminentemente cultural e ideológica, pois apresentam diferentes visões de mundo de diferentes sujeitos em diferentes contextos e promovem a reapropriação do mundo ao mesmo tempo (COPE; KALANTZIS, 2009). Este estudo traz uma grande contribuição para a área de Linguística Aplicada e espera-se motivar outros professores na produção de aulas expansivas em que o ensino da língua seja construído em contexto social relevante para as turmas, juntamente a outras competências comunicativas, motivando-os no estabelecimento de seus estudos autônomos e críticos-reflexivos.

Palavras-chave: linguística aplicada; letramentos digitais; ensino de língua inglesa; memes

\footnotetext{
${ }^{1}$ Doutor e mestre em Estudos Linguísticos pelo curso de Pós-graduação da Faculdade de Letras da Universidade Federal de Minas Gerais, tendo graduado em Licenciatura em Língua Inglesa pela mesma universidade. aldelfino@gmail.com

2 Possui graduação em Letras - Inglês pela Universidade Federal de Ouro Preto(2017). evandrolmsouza@gmail.com

3 Possui graduação em Letras Licenciatura Inglês pela Universidade Federal de Minas Gerais (2002), mestrado em Estudos Linguísticos pela Universidade Federal de Minas Gerais (2004) e doutorado pelo Programa de Pós Graduação em estudos Linguísticos pela mesma instituição (2009). shirlene.o@ifmg.edu.br
} 


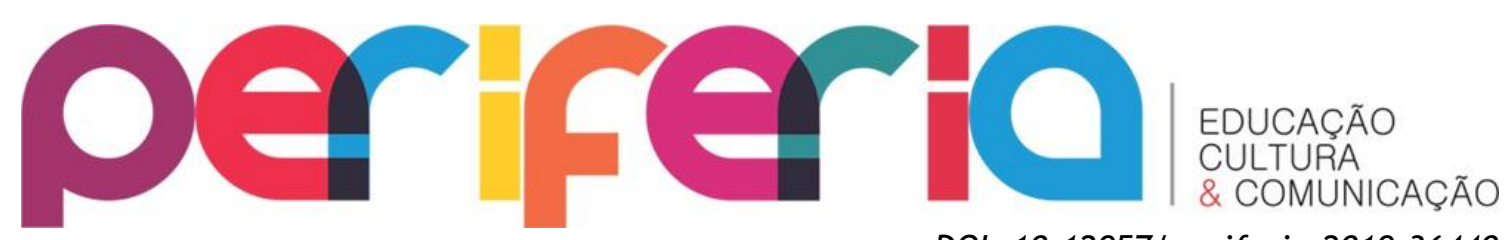

DOI: $10.12957 /$ periferia.2019.36440

\title{
THE CONSTRUCTION OF MEMES AS AN ENGLISH LANGUAGE TEACHING TOOL
}

\begin{abstract}
The advent of globalization and the multiplicity of semiotic channels, media or modes of communication created from new technologies and social media have driven changes in the school context that necessarily take into account the growing linguistic and cultural diversity present worldwide (COPE, KALANTZIS, 2000). The purpose of this article is to present and discuss a didactic sequence of English language teaching through the memes analysis, construction and sharing online. The theoretical contribution is based on the Functional Theories of Applied Linguistics, with special focus on the theories of literacy that constitute Interactionism. The analytical study of memes is discussed on the basis of structural, semantic and critical issues, in order to favor the valorisation of the author's production of memes. From this perspective of semiotic analysis, creativity, dynamism, innovation, interest and motivation, the results point to the representation and recontextualization of realities in an eminently cultural and ideological way, since they present different worldviews of different subjects in different contexts and promote the reappropriation of the world at the same time (COPE; KALANTZIS, 2009). This study makes a great contribution to Applied Linguistics area and it is hoped to motivate other teachers in the production of expansive classes in which the language teaching is constructed in a social context relevant to the students, along with other communicative competences, motivating them in the establishment of their autonomous and critical-reflective studies.
\end{abstract}

Keywords: applied linguistics; digital literacy; english language teaching 


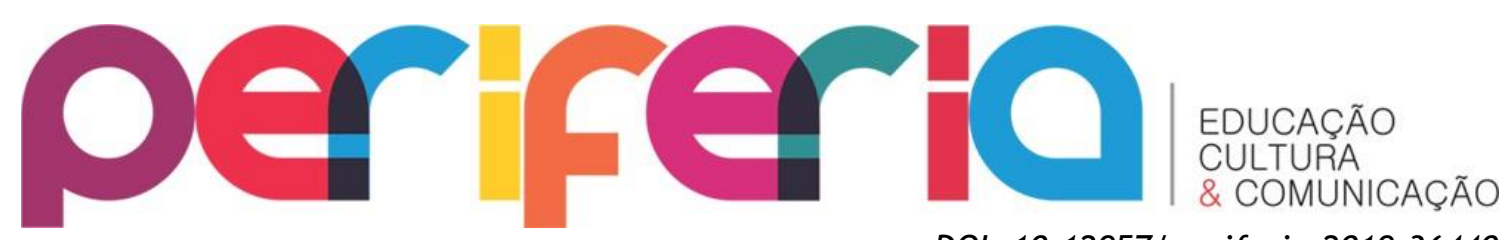

DOI: $10.12957 /$ periferia.2019.36440

\section{LA CONSTRUCCIÓN DE MEMES COMO HERRAMIENTA DE ENSEÑANZA DE LA LENGUA INGLESA}

\section{Resumen}

El advenimiento de la globalización y de la multiplicidad de canales, medios o modos semióticos de comunicación creados a partir de nuevas tecnologías y medios sociales impulsaron cambios en el contexto escolar que necesariamente pasan a considerar la creciente diversidad lingüística y cultural presente mundialmente (COPE, KALANTZIS, 2000). El objetivo de este artículo es presentar y discutir una secuencia didáctica de enseñanza de lengua inglesa a través del análisis, construcción y compartición de memes en internet. El aporte teórico es pautado en las Teorías Funcionales de la Lingüística Aplicada, con especial enfoque en las teorías de letramento que constituyen el Interaccionismo. El estudio analítico de memes se discute sobre la base de cuestiones estructurales, semánticas y críticas, a fin de propiciar la valorización de la producción autoral de los memes. A partir de esta perspectiva de análisis semiótica, de la creatividad, del dinamismo, de la innovación, del interés y de la motivación, los resultados apuntan a la representación y recontextualización de las realidades de forma eminentemente cultural e ideológica, pues presentan diferentes visiones de mundo de diferentes sujetos en diferentes los contextos y promueven la reapropiación del mundo al mismo tiempo (COPE, KALANTZIS, 2009). Este estudio trae una gran contribución al área de Lingüística Aplicada y se espera motivar a otros profesores en la producción de clases expansivas en que la enseñanza de la lengua sea construida en contexto social relevante para los alumnos, junto a otras competencias comunicativas, motivando en el ámbito el establecimiento de sus estudios autónomos y críticosreflexivos.

Palabras clave: lingüística aplicada, letras digitales, enseñanza de inglés 


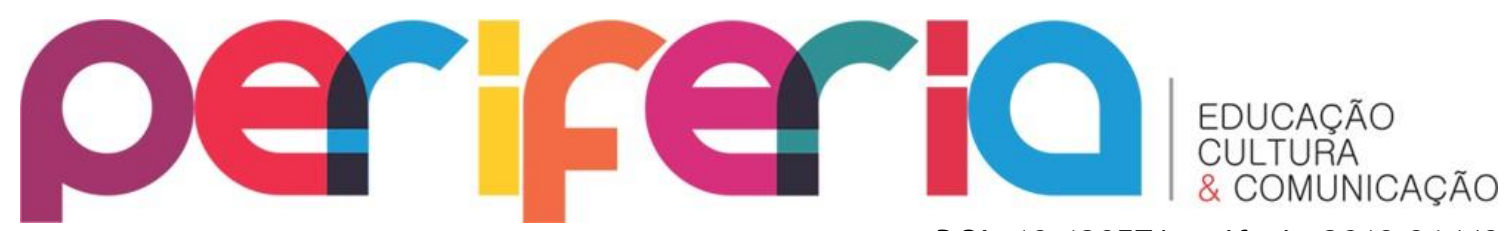

INTRODUÇÃO

DOI: $10.12957 /$ periferia.2019.36440

0 conceito inicial de memes tem origem no conceito elaborado por Dawkins (1976):

É considerado como uma unidade de informação que se multiplica de cérebro em cérebro ou entre locais onde a informação é armazenada (como livros). No que diz respeito à sua funcionalidade, o meme é considerado uma unidade de evolução cultural que pode de alguma forma autopropagar-se. Os memes podem ser ideias ou partes de ideias, línguas, sons, desenhos, capacidades, valores estéticos e morais, ou qualquer outra coisa que possa ser aprendida facilmente e transmitida como unidade autônoma. ${ }^{4}$

Em contextos de produção de textos, ele ganha a dimensão de um gênero textual híbrido em que a imagem e o texto se completam. Enquanto gênero, os memes possuem uma alta capacidade de replicação de ideias e são altamente dinâmicos e efêmeros. Sempre que uma determinada ideia, conceito, cena ou acontecimento atinge relevância social, pode-se criar um meme que pode ser compartilhado e alterado infinitas vezes.

Os assuntos abordados são os mais diversos possíveis, desde conteúdos leves e recreativos até críticas sociais e políticas. Algumas vezes, os memes podem contribuir na manutenção dos estereótipos ou questioná-los, proporcionando um pensamento crítico em relação aos assuntos de interesse na comunidade. Enquanto replicador de ideias em contexto linguístico e digital, Blackmore (2000) afirma que:

[...] quando você imita alguma outra pessoa, algo é passado adiante. Este 'algo' pode então ser passado adiante novamente, e de novo, e assim ganhar vida própria. Podemos chamar esta coisa uma ideia, uma instrução, um comportamento, uma informação... mas se nós vamos estudá-la precisamos dar a ela um nome. Felizmente, há um nome. É o 'meme’. (p. 4, tradução nossa).

${ }^{4}$ Disponível em https://pt. wikipedia.org/wiki/Meme 


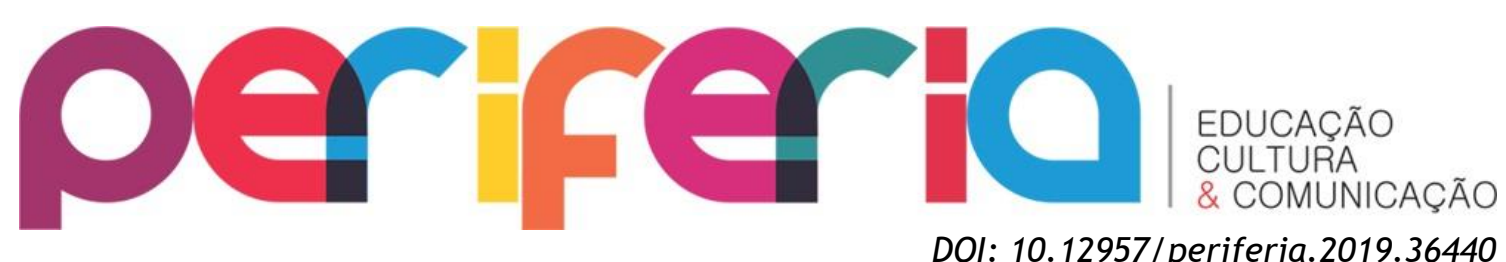

Nesse sentido, os memes são exemplos de produção textual da contemporaneidade, refletindo as opiniões, ideologias e posicionamentos das pessoas. Assim, destaca-se o aspecto cultural e artístico, os quais demandam criatividade e raciocínio engenhoso para que uma ideia seja resgatada da memória cultural coletiva e seja reapresentada nos memes com distintas roupagens a cada retorno, perpassando a estrutura e chegando na semântica da língua para produzir novos significados.

Embora um quarto da comunicação feita na internet seja em língua inglesa ${ }^{5}$, estudos apontam o Brasil como uma das comunidades mais participativas da internet e das redes sociais, mesmo com limitações linguísticas e de cunho técnico (IBGE, 2016; MARCONDES, 2011). Os internautas brasileiros não abrem mão do espaço cibernético e suas múltiplas possibilidades de sustentar e reproduzir conteúdo geral em tempo instantâneo.

\section{O uso de memes em práticas pedagógicas}

Em um contexto escolar, os memes abrem perspectivas quanto a novas práticas de leitura e escrita, desde que inseridas em uma metodologia que motive os alunos a enxergarem o potencial comunicativo dos textos produzidos por eles mesmos através de gêneros populares, isto é, que tangenciam a realidade dos alunos.

Contudo, o que se observa ainda hoje é o baixo emprego desse gênero em materiais didáticos. Uma das possíveis explicações é a manutenção de práticas na formação de professores que não estimulam a exploração de gêneros textuais digitais em sala de aula. Além disso, ainda predomina uma perspectiva estrutural no ensino de línguas, sejam elas maternas ou adicionais. As habilidades de expressão (leitura, escrita, enunciação oral e interpretação auditiva) são, assim, ensinadas fora de contextos de uso real, gerando um distanciamento entre um modelo geral e pouco representativo da realidade dos alunos enquanto usuários da língua. Esse distanciamento gera resistência e

\footnotetext{
${ }^{5}$ Dados disponíveis em https://www.internetworldstats.com/stats7.htm

Periferia, v. 11, n. 1, p. 140-161, jan./abr. 2019
} 


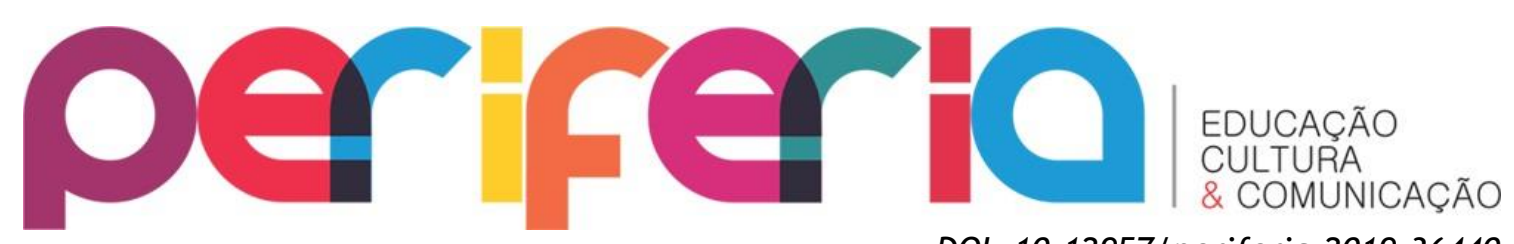

DOI: $10.12957 /$ periferia.2019.36440 dificuldades para os alunos, pois eles não se enxergam nesses modelos ou práticas ofertadas em materiais homogêneos (FREIRE, 1968).

A premissa por aqui seria de que o estudo dos conteúdos escolares deveria acontecer de forma interdisciplinar, relacionando os conteúdos sistematizados com variáveis da realidade dos alunos. Assim, eles teriam condições de confrontar suas concepções de mundo com o conhecimento que é oferecido nas escolas, fazendo uma leitura crítica do conhecimento.

De acordo com Pennycook (2006), a Linguística Aplicada Crítica possibilita o trabalho com um conjunto de novas dimensões antes consideradas fora da área de interesse, como identidade, sexualidade, ética, desigualdade e alteridade. Dessa forma, o processo de ensino e aprendizagem crítica de línguas ultrapassa a camada estrutural comparando-a com as questões culturais, econômicas, identitárias e éticas.

$\mathrm{Na}$ área da Linguística Aplicada, pensando-se também o ensino de línguas, se encontram as teorias de letramentos como vias para se atingir os objetivos acima, assim como reforça Kleiman (1995), quando afirma que “os estudos do letramento têm como objeto de conhecimento os aspectos e os impactos sociais do uso da língua escrita" (p. 1).

Os conceitos de letramento surgiram no Brasil por volta da década de 80 a partir da distinção entre os termos alfabetização e letramento, sendo o primeiro a prática de ensino das formas da língua e das habilidades mecânicas de leitura e escrita, enquanto o segundo significa o trabalho com a língua dentro das necessidades e demandas sociais contemporâneas, incorporando a realidade dos alunos como fator crucial do processo, assumindo que o uso da língua sempre parte de um posicionamento ideológico carregado de valores sociais, subjetivos e complexos (STREET, 1984).

A escola seria a agência de letramento mais fundamental da estrutura de uma sociedade, sendo ali um ambiente para a promoção de práticas discursivas em que os alunos sejam desafiados a perceberem os diferentes tipos de texto não só como um conjunto de estruturas morfossintáticas, mas como uma unidade em que a subjetividade de alguém, vinculada à teia de textos 


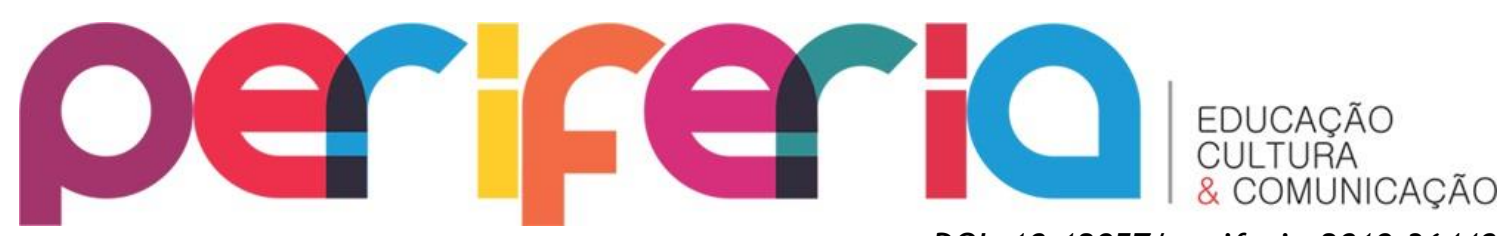

DOI: $10.12957 /$ periferia.2019.36440

existentes no mundo, apresenta um posicionamento ideológico e cultural (KLEIMAN, 1995).

Quando um aluno é orientado a produzir uma carta, por exemplo, ele deve considerar as formas estáveis da língua que geralmente pertencem ao gênero. Além das formas, os gêneros têm um objetivo social. No caso da carta, por exemplo, a produção do texto tem como fim o relato de uma experiência ou uma requisição formal ao leitor. Certamente é mais motivador e eficaz orientar os alunos a um trabalho colaborativo intenso ao invés de deixá-los escrever individualmente, descartando o objetivo social pressuposto pela redação para elevar as formas de um modelo genérico de carta como única possibilidade para a escrita do gênero.

Reforçando essa ideia, Rojo (2012) expande a noção de letramento para o letramento digital:

\begin{abstract}
"[...] trabalhar com multiletramentos pode ou não envolver (normalmente envolverá) o uso de novas tecnologias da comunicação e de informação ('novos letramentos'), mas caracteriza-se como um trabalho que parte das culturas de referência do alunado (popular, local, de massa) e de gêneros, mídias e linguagens por eles conhecidos, para buscar um enfoque crítico, pluralista, ético e democrático - que envolva agência - de textos/discursos que ampliem o repertório cultural, na direção de outros letramentos" (p. 8).
\end{abstract}

Formas de comunicação e transmissão de informação pontuais e precisas são demandas de uma sociedade capitalista e globalizada. Essas demandas estruturais sustentam o formato da pirâmide social e quais papéis e funções serão atribuídos aos diferentes “cargos” sociais. Sendo a internet, portanto, um espaço de comunicação global, a escola deve estar preparada para propiciar práticas educacionais que atinjam os objetivos requisitados pela vida contemporânea e incorporar não só infraestrutura física, mas também condições intelectuais de avançar os debates para a esfera social, não se restringindo a um escopo de conhecimentos descontextualizados.

Para Bakhtin (1988), um gênero é composto por características comuns entre si, embora também apresente características que distinguem cada texto 


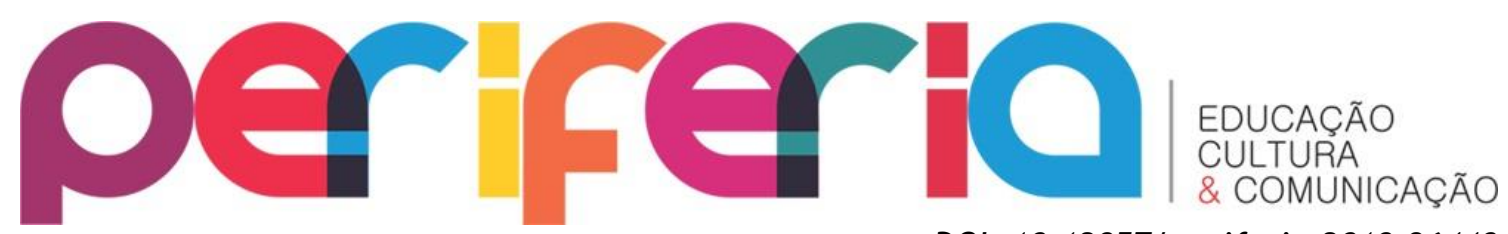

DOI: $10.12957 /$ periferia.2019.36440 como único. Dessa forma, quando ensinamos língua nas escolas, devemos levar em conta as diversas amostras linguísticas existentes no mundo para promover momentos de reflexão e pensamento crítico constantes:

A lógica de uma proposta de ensino e de aprendizagem que busque promover letramentos múltiplos pressupõe conceber a leitura e a escrita como ferramentas de empoderamento e inclusão social. Some se a isso que as práticas de linguagem a serem tomadas no espaço da escola não se restringem à palavra escrita nem se filiam apenas aos padrões socioculturais hegemônicos. Isso significa que o professor deve procurar, também, resgatar do contexto das comunidades em que a escola está inserida as práticas de linguagem e os respectivos textos que melhor representam sua realidade. (BAKHTIN, 1988, p. 28).

A partir desse viés é possível encarar o ensino/aprendizagem de línguas como uma atividade autônoma, proativa e sócio-histórica em que os envolvidos devem pesquisar e construir textos abrangentes, ligados ao contexto social da escola e de si próprios. Assim, nega-se o papel do professor autoridade, sendo aquele que transmite conteúdo para os alunos de forma estável, precisa e exata.

\section{O PERCURSO DA SEQUÊNCIA DIDÁTICA}

Apresentamos uma sequência didática pautada nos letramentos digitais e na complexidade da construção dos gêneros discursivos durante um processo dialógico. Ela foi planejada por um graduando em Letras e participante do Programa Institucional de Bolsas de Iniciação à Docência (PIBID) da Universidade Federal de Ouro Preto e dois professores do Instituto Federal de Minas Gerais em Ouro Preto. Participaram cerca de 170 alunos de diversos cursos técnicos integrados ao ensino médio do mesmo Instituto.

A sequência se iniciou com a apresentação aos alunos dos objetivos da aula. Em seguida, os alunos foram orientados a responder a um questionário 


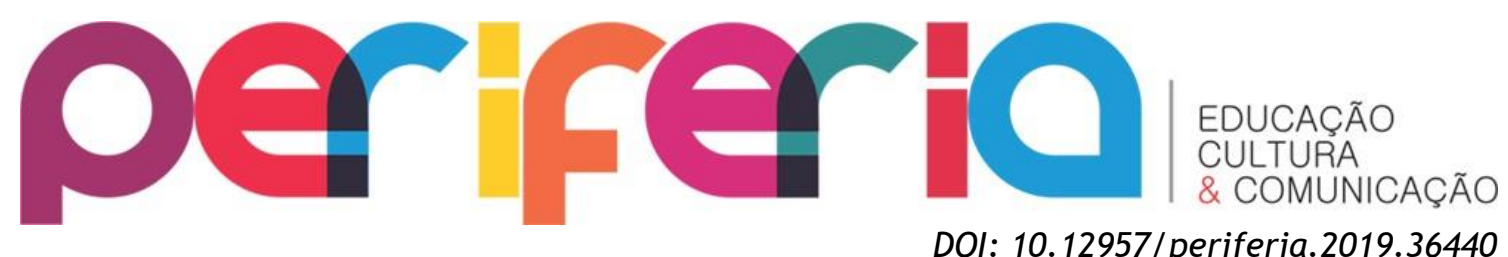
online usando os seus próprios telefones celulares ${ }^{6}$. Após o preenchimento do questionário, o professor apresentou um vídeo em língua inglesa aos alunos sobre "os dez melhores memes da internet" 0 vídeo apresenta a origem de alguns memes mais populares na internet e em que contexto eles são utilizados. Após a exibição do vídeo, abriu-se uma rodada de discussão entre os alunos sobre o seu conhecimento prévio sobre o gênero meme. As opiniões e os fatos apresentados pelos alunos foram registrados pelos professores no quadro. $\mathrm{Na}$ próxima etapa, foram apresentados memes mais recentes em slides para que os alunos apontassem a sua familiaridade e o contexto de uso desses memes e as características estruturais típicas do gênero. A etapa final foi a produção autoral de memes pelos alunos utilizando dispositivos como telefones, tablets e laptops. Os alunos também tiveram acesso a apps e sites que automatizam a produção de memes, como o Meme Generator ${ }^{8}$. Os alunos foram orientados a publicar os memes produzidos na plataforma online Padlet ${ }^{9}$.

\section{ANÁLISE E DISCUSSÃO DO PROCESSO}

Nesta seção serão apresentados os resultados do questionário inicial online, da sequência didática, dos memes com posterior análise do conteúdo e dos questionários finais.

\section{Questionário inicial Online}

Os 170 alunos responderam ao questionário inicial usando os telefones celulares. Esse questionário tinha duas seções: a primeira abordava questões sobre o tempo de acesso à internet, atividades e redes sociais preferidas, além das atividades obrigatórias que eles desempenhavam virtualmente. A segunda seção era especificamente sobre os memes e tinha o objetivo de ativar os

\footnotetext{
${ }^{6} \mathrm{O}$ questionário está disponível em http: / / bit.ly/questmeme

7 Top 10 Internet memes. Disponível em https://www.youtube.com/watch?v=rRz6h9Ey9rE

${ }^{8}$ Disponível em https: //imgflip.com/memegenerator

${ }^{9}$ Memes ESL BR. Disponível em https://padlet.com/aldelfino/memes
} 


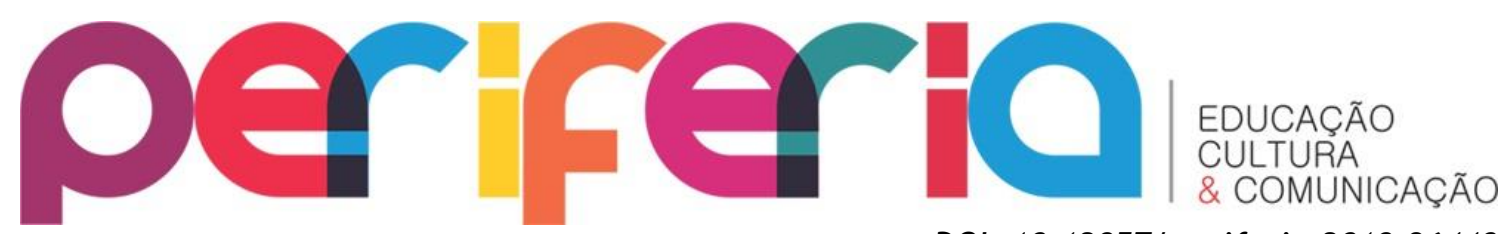

DOI: $10.12957 /$ periferia.2019.36440 conhecimentos prévios dos alunos sobre os memes, suas características, origem, etc.

\section{Experiências dos Alunos com a Internet}

A tabela abaixo mostra a porcentagem de alunos de acordo com o tempo conectado à internet.

Tabela 1. Resultado da pergunta Quanto tempo diário você passa conectado na internet?

\begin{tabular}{|l|l|}
\hline Tempo (em horas) & Porcentagem \\
\hline 1 & $2,4 \%$ \\
\hline 2 & $6,7 \%$ \\
\hline 3 & $12,1 \%$ \\
\hline 4 & $7,3 \%$ \\
\hline 5 & $16,4 \%$ \\
\hline $6+$ & $55,2 \%$ \\
\hline
\end{tabular}

Fonte: dados da pesquisa

Esses dados corroboram os resultados da pesquisa PNAD do IBGE (2016) que mostram que os brasileiros mais jovens passam cada vez mais tempo na internet usando os celulares para receber e enviar mensagens e conteúdos. Essa pesquisa também reforça essa mudança de hábito a partir do advento das redes sociais, principalmente do aplicativo Whatsapp.

As redes sociais são mencionadas pelos alunos como as atividades preferidas na internet, destacando-se Facebook (144), Whatsapp (94), Instagram (81), Snapchat (62) e o Youtube (37). A maioria dessas plataformas é utilizada de forma livre e espontânea para diversão. As atividades envolvem o acesso e compartilhamento de textos, jogos, arquivos de áudio e vídeo, a conversa por chats, comentários em páginas, acompanhar notícias e "stalkear" pessoas.

Os alunos relataram que há atividades que são obrigados a desenvolver online, sendo a maioria relacionada ao contexto escolar, principalmente nas 


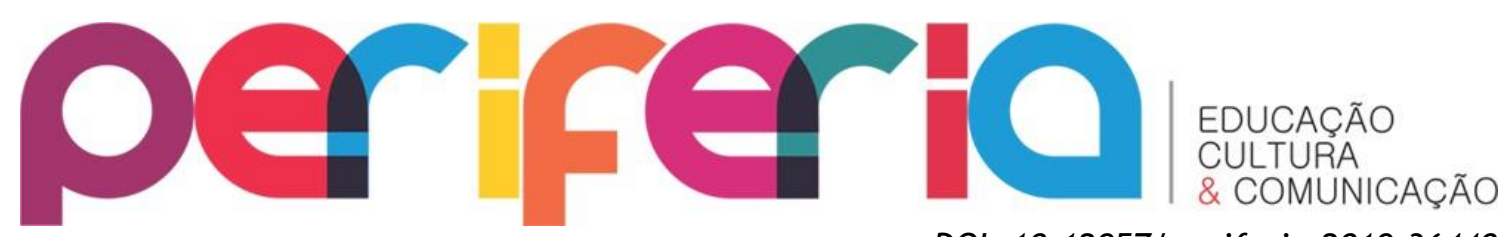

DOI: $10.12957 /$ periferia.2019.36440 disciplinas de Língua Inglesa, Física e Geografia. Entre essas atividades se destacam pesquisas e trabalhos escolares, incluindo o acesso a videoaulas; verificação e envio de e-mails; comunicação com o grupo da sala; recados importantes da escola; acesso a notas no sistema acadêmico; geração de boletos; pagamentos; agendamento de consultas; compras; cadastro para viagens e excursões; blogs escolares; traduções; materiais didáticos.

\section{Conhecimento Prévio dos Alunos Sobre Memes}

As escolhas lexicais dos alunos remetem ao texto imagético criado para o entretenimento, como mostra a nuvem de palavras criada com base na frequência lexical:

Figura 1. Itens lexicais mais frequentes para definir o gênero Meme

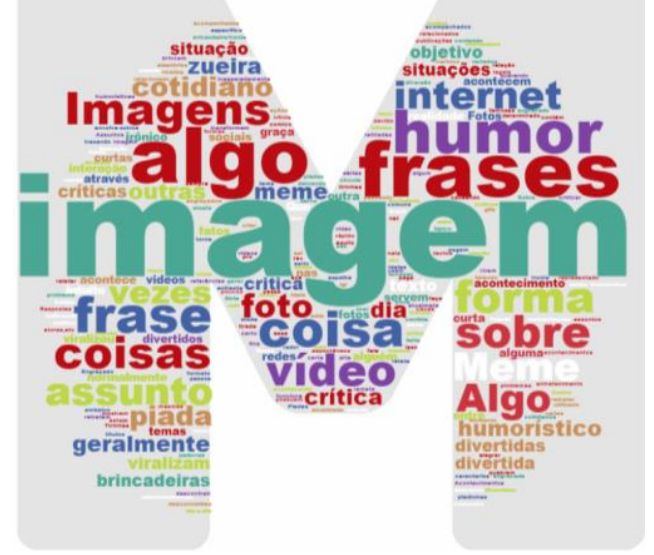

Fonte: dados da pesquisa

As definições propostas pelos alunos sobre o gênero foram feita em três dimensões: sua velocidade de propagação, sua composição e sua função. De acordo com os alunos, os memes viralizam e são construídos com imagens, vídeos e frases relacionadas a algum acontecimento do cotidiano e têm funções de comunicação, entretenimento, posicionamento crítico através de humor, sátira e ironia. Abaixo seguem algumas das definições apresentadas pelos alunos participantes: 


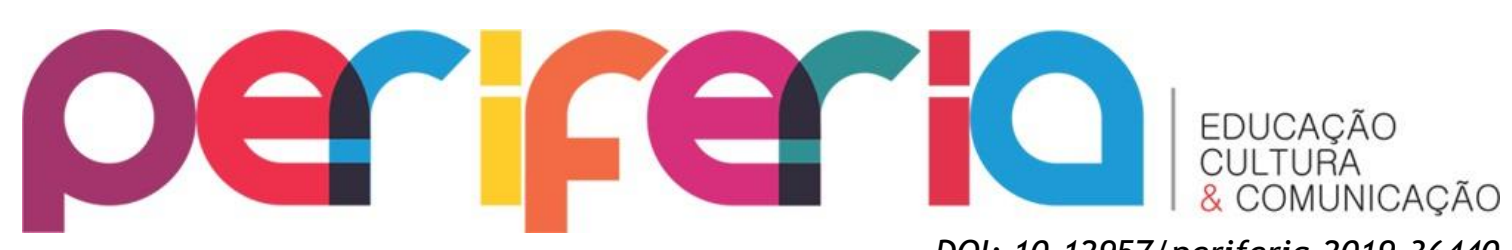

DOI: 10.12957/periferia.2019.36440

Fotos com frases engraçadas (Lucas)

É algo engraçado relacionado a algo popular ou que esteja em alta na net (Leila)

É uma imagem com uma frase curta de humor, irônico $e$ etc... (Bruna)

É uma zoeira (Daniela)

E um vídeo ou uma imagem que faz uma pessoa triste se alegrar (Higor)

Tirinhas descontraídas de temas variados (Ivi)

Uma coisa que viraliza; pode ser engraçado ou não, sempre puxa para ironia (Samuel)

É imagem ou vídeo que viralizou na internet sobre um assunto do momento $e$ as pessoas pegam esse assunto $e$ fazem uma brincadeira com ironia (Raissa)

São imagens de humor que mostram ações e fatos do nosso cotidiano (Pedro)

Uma forma engraçada e divertida de se descontrair e às vezes criticar algo. Ele é uma imagem, vídeos, gifs que tem o objetivo de fazer outras pessoas rirem (Taynara)

Uma foto ou vídeo que envolve política, fotos de atores,etc. (Vitória)

Meme é um tipo de zueira $\mathrm{cm}$ td crítica do a nossa sociedade e deixando aquilo q e serio mais Igl (Vinicius)

Uma crítica divertida e engraçada aos problemas que geralmente o Brasil enfrenta. Ele tem uma foto, um vídeo ou uma música que se espalha rápido geralmente engraçado.

É algo ou "alguém" que viralizou (Sara)

Meme é uma forma de interação com as coisas que acontecem ao redor para com o seres. Às vezes usam para fazer uma crítica às vezes passa um conhecimento e na forma de fotos ou vídeos engraçados que viralizam na internet (Paula)

Os resultados do questionário mostram que há uma grande variedade de temas utilizados para a construção dos memes, nos quais podemos destacar temas históricos, políticos, esportivos, humorísticos, cotidianos, religiosos, amorosos, escolares e entretenimento em geral. Um aspecto importante a ser destacado é que, sendo o meme um gênero superfluido e que dá suporte para assuntos imediatamente cotidianos, vários dos temas e imagens de apoio caem rapidamente de uso. Assim, vários dos subtemas levantados pelos alunos durante o questionário já não são mais utilizados por eles mesmos, como o "cepo de madeira", em que um menino aparece em vídeo brincando com pólvora em um toco de madeira.

A maioria dos memes acessados e compartilhados pelos alunos foram em Língua Portuguesa (95,8\%). Cerca de 60\% dos alunos dizem saber criar e compartilhar memes, embora $88,6 \%$ não souberam informar a origem desses 


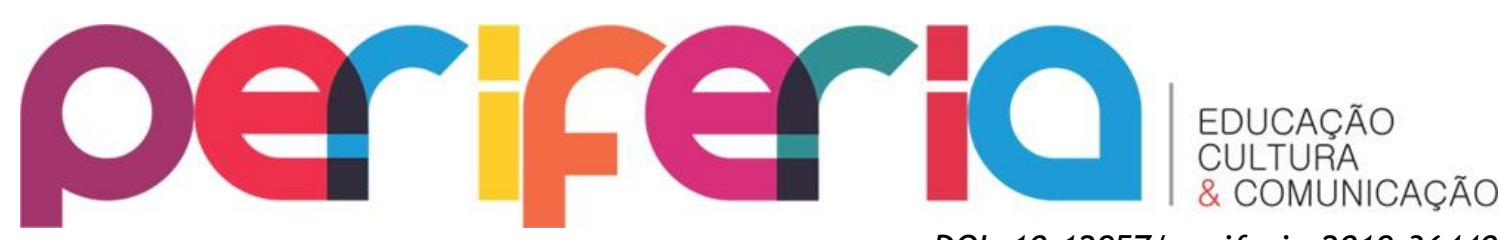

DOI: $10.12957 /$ periferia.2019.36440 mesmos memes. Muitos alunos relataram que tiveram acesso ao gênero a partir de 2012, e que muitos dos memes têm origem na década de 1990. Essa questão será discutido no próximo item.

\section{Apresentação do vídeo "10 melhores memes da internet"}

Uma das características mais relevantes desse gênero é a sua rápida propagação ou viralização e como ele é rapidamente readaptado, servindo de base para paródias. Os alunos rapidamente apontaram essa característica que os permite aproveitar memes famosos para criar as suas próprias versões.

Outra característica é a efemeridade com que os memes surgem e desaparecem Os memes apresentados no vídeo, em sua maioria, não foram reconhecidos pelos alunos. Uma possível explicação é que vários desses memes foram criados em uma época antes da popularização dos memes em dispositivos móveis. Um exemplo é o meme Rickroll, criado a partir de um trecho da música "Never Gonna Give You Up" do cantor e compositor inglês Rick Astley. De acordo com o site Know Your Meme ${ }^{10}$, Rickroll foi criado em 2007, época em que os smartphones não haviam se popularizado. Além disso, os alunos do ensino médio eram crianças na faixa dos 5 a 7 anos na época de criação desse meme, o que pode ter contribuído para o seu baixo reconhecimento. Por fim, é importante salientar que os memes, embora tenham exemplos de propagação global, também podem se restringir a contextos localizados justamente porque tratam de um tema de interesse local.

${ }^{10}$ Disponível em https://knowyourmeme.com/memes/rickroll 


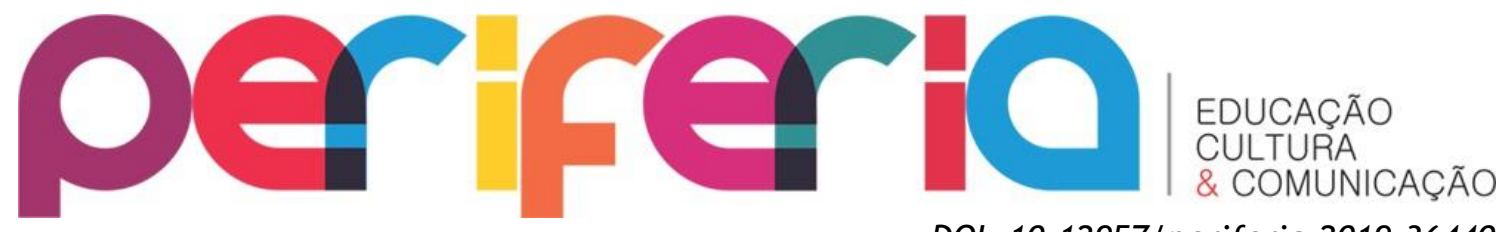

Figura 1: imagem do meme Rickroll

DOI: 10.12957/periferia.2019.36440

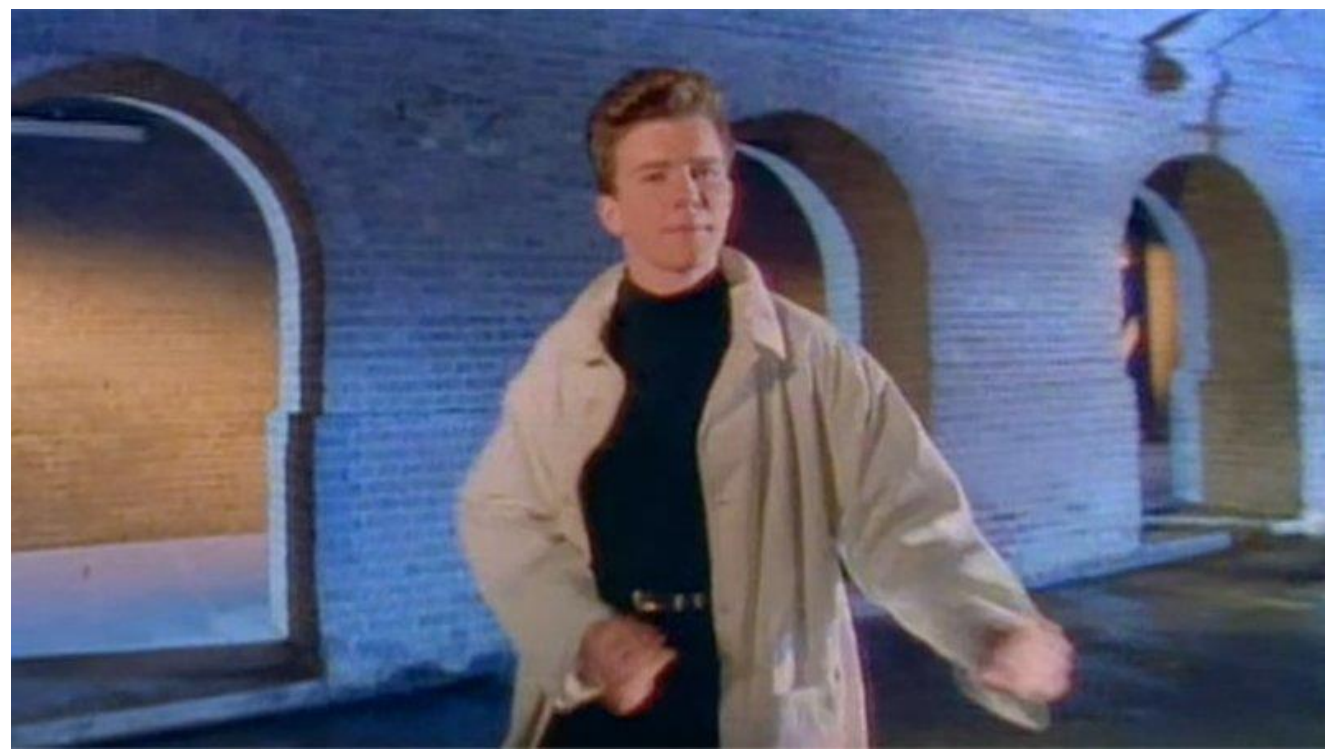

Fonte: https://i.kym-cdn.com/entries/icons/original/000/000/007/bd6.jpg

\section{Produção e Publicação dos Memes}

Os alunos participantes produziram 259 memes, que foram categorizados e analisados de acordo com o conteúdo das frases e das imagens. A maioria dos memes foi construída a partir do sintagma nominal (When + substantivo ou pronome) e muitos deles foram criados a partir de imagens dos próprios alunos. A tabela 1 a seguir apresenta os temas e subtemas mais frequentes:

Tabela 1: Distribuição dos memes por temas e subtemas.

\begin{tabular}{|l|l|}
\hline \multicolumn{2}{|c|}{ DISTRIBUIÇÃO DOS MEMES POR TEMAS E SUBTEMAS } \\
\hline \multicolumn{1}{|c|}{ TEMAS E SUBTEMAS } & FREQUÊNCIA \\
\hline estereótipos dos brasileiros & 89 \\
\hline situação Política do Brasil & 39 \\
\hline Contexto Escolar & 48 \\
\hline comida e bebida & 15 \\
\hline eu (persona) & 16 \\
\hline racismo & 6 \\
\hline
\end{tabular}

Fonte: dados da pesquisa 


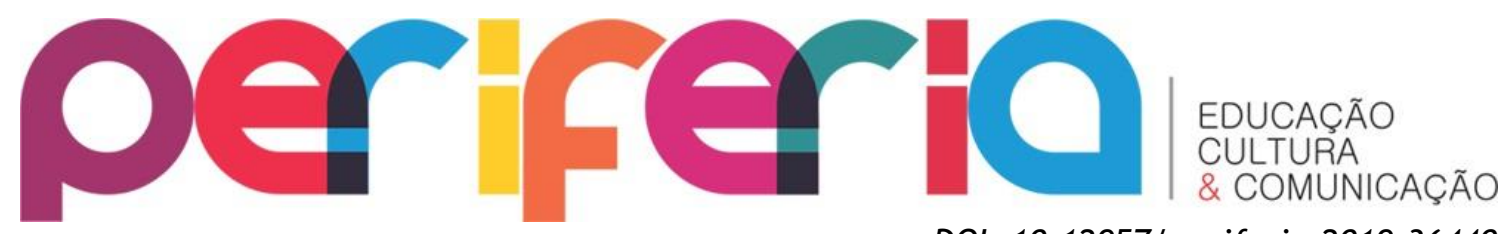

DOI: $10.12957 /$ periferia.2019.36440

Os memes mais frequentes foram os relacionados a estereótipos dos brasileiros (89), provavelmente por causa da unidade didática que trabalhou com questões relacionadas aos estereótipos na ocasião. A maioria dos estereótipos são relacionados ao carnaval, ao samba e ao futebol. Além disso, devido a região em que os alunos se encontram, vários memes foram criados a partir dos estereótipos dos mineiros que são caipiras, falam uai, comem pão de queijo e escutam músicas sertanejas.

Figura 2

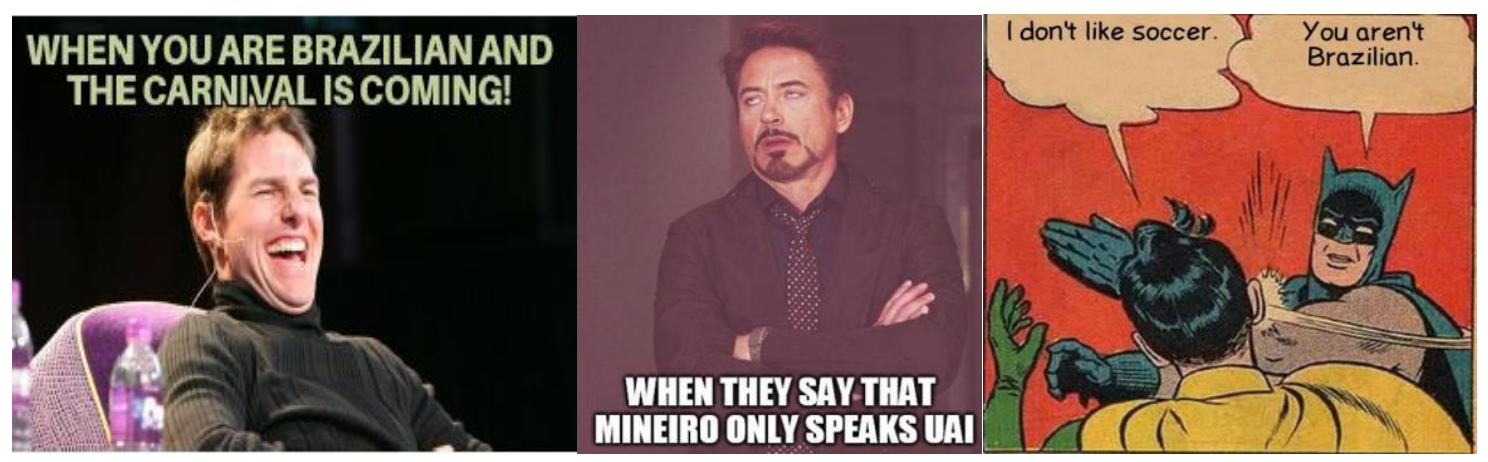

Fonte: dados da pesquisa

Além disso, memes relacionados ao contexto escolar (48) e e a situação política do Brasil (39) também foram frequentes. Os memes relacionados às questões da política e economia brasileira foram criados para protestar contra o impeachment e golpe do novo presidente, para expressar a insatisfação, a falta de confiança nos governantes e denunciar a corrupção constante no país, além de criticar o comportamento dos brasileiros que estão apáticos com a situação. 


\section{periferio}

Figura 3

DOI: $10.12957 /$ periferia.2019.36440

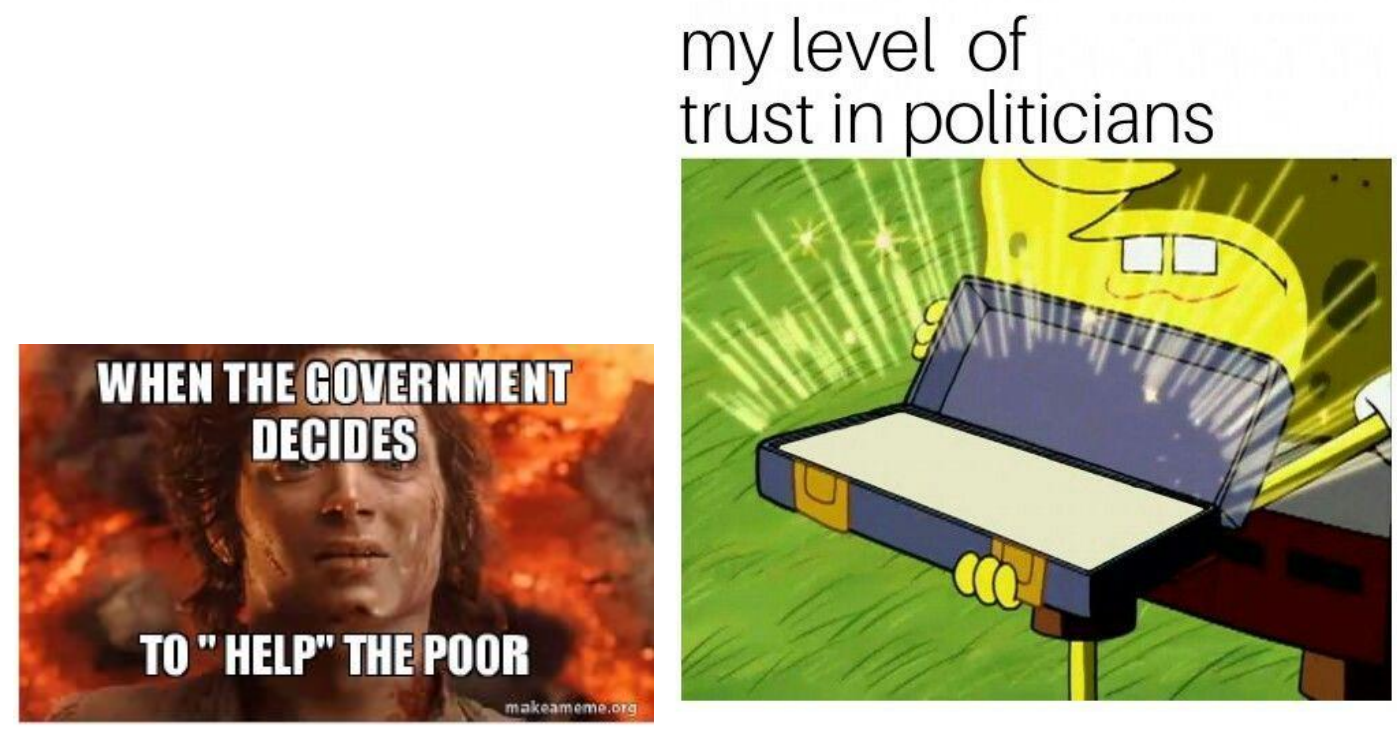

Fonte: dados da pesquisa

Os memes relacionados ao contexto escolar se referem à rotina dos alunos que estudam nos Institutos Federais. Os alunos do ensino médio estudam em um sistema integrado e tem aulas das $7 \mathrm{~h}$ às $17 \mathrm{~h}$. Os professores são geralmente muito exigentes e a carga de estudo e trabalhos a serem feitos em casa é grande. Além disso, há memes que relatam um pouco do que vivenciam na relação estabelecida com os professores, colegas de classe e com a comunidade escolar em geral.

Figura 4
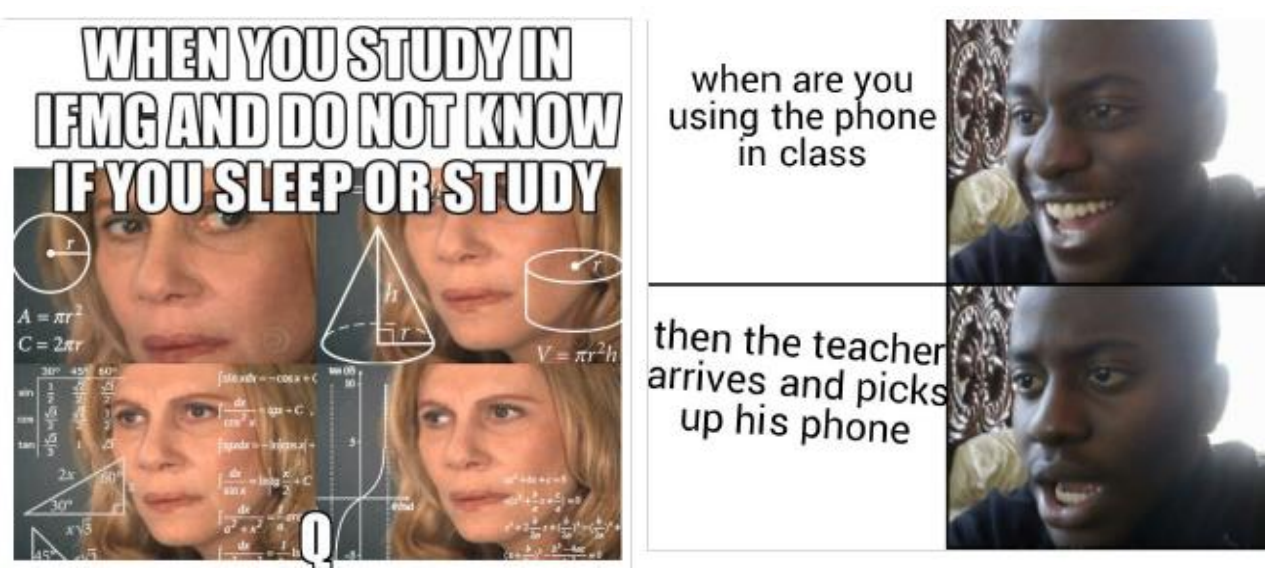

Fonte: dados da pesquisa

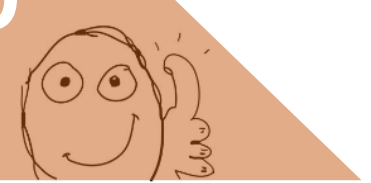




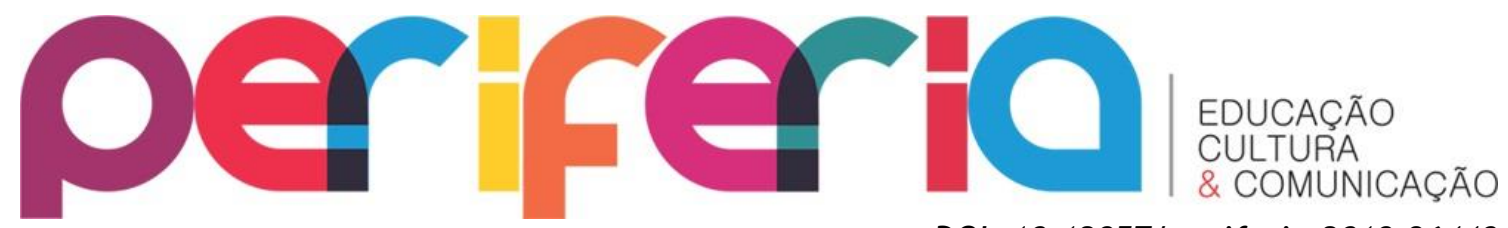

DOI: $10.12957 /$ periferia.2019.36440

Outros memes foram menos frequentes e relacionados a alimentação, ao eu (persona) e ao racismo.

Figura 5

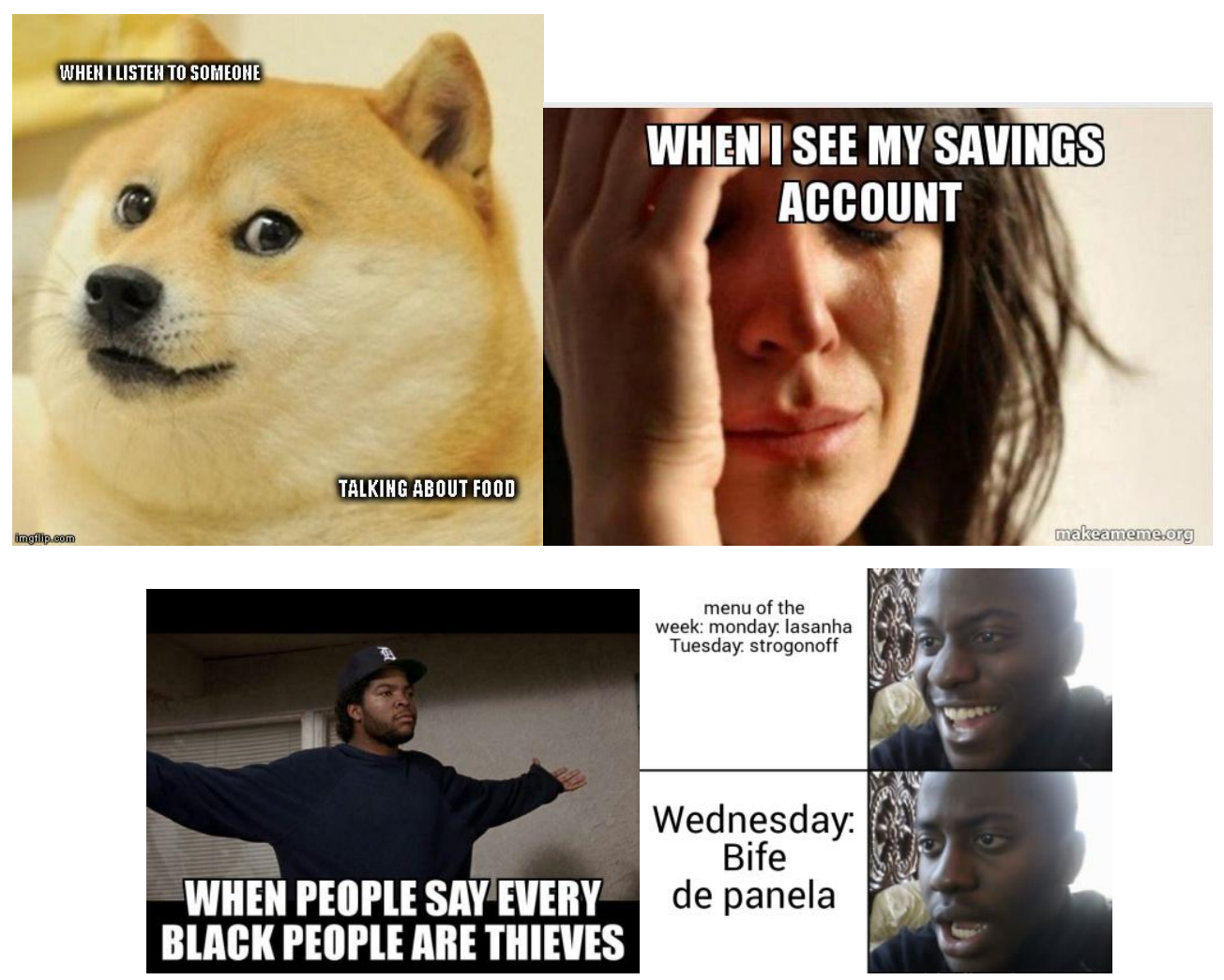

Fonte: dados da pesquisa

Os memes relacionados ao tema da "comida e bebida" retratam a gula "When people ask when I want to eat... every day, all day long, all the time", fazem referência ao restaurante escolar "When I arrive at the restaurant with the expired ticket and the aunt doesn't let me in", remetem ao entretenimento "When they call me and it is open bar" ao fato de os mineiros gostarem das comidas típicas da região.

Os memes sobre o tema do racismo também foram construídos com o chunk iniciado pelo advérbio "When" mais um sintagma nominal e nesse caso, teve a função de protestar e demarcar o posicionamento contra a prática racista e ao colonialismo: "when somebody makes racist jokes", "when you are in love and the girl is racist." 


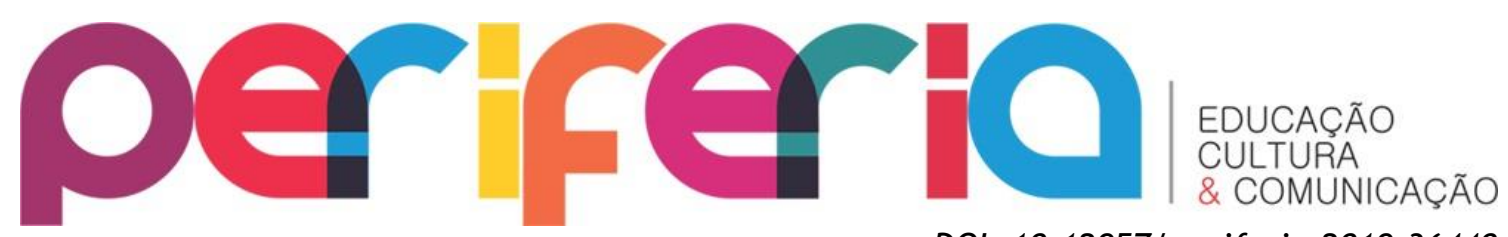

DOI: $10.12957 /$ periferia.2019.36440

Por fim, existem os memes relacionados ao tema "eu (persona)" que se configuram de forma bem variada. Em muitos memes, os autores se posicionam em primeira pessoa para criticar a situação política nacional: “Me watching politicians stealing Brazil", para falar de amor "When I find out that the crush is single", para reclamar dos estudos ou para enaltecer ou criticar a própria forma e aparência física.

Esses dados nos indicam mais uma vez como a função social dos memes está relacionada a um contexto imediato de comunicação. A grande maioria dos memes produzidos estão relacionados a temas recentes e/ou frequentes no cotidiano dos alunos.

\section{Avaliação da oficina de Memes}

De maneira geral, os alunos afirmam que gostaram de participar da oficina de análise e construção dos memes. Eles nos informam que a prática foi interessante, ajudando-os a aprender a língua de forma prática, como mostra os excertos abaixo:

Apesar de estarmos no Brasil foi difícil parar e pensar em "estereótipos" brasileiros, mas no final deu tudo certo. Na hora de publicar o meme no site eu e sala inteira tivemos dificuldades, pois o site era lento e travava muito (Raissa)

Adorei participar, pois gosto muito de memes. No princípio tive dificuldade para posta-lo, mas depois que aprendi, vi que era muito prático. Posteriormente usei a ferramenta de memes para produzir outros, pessoais (Lucas)

Tive dificuldade com o vídeo por estar todo em inglês, mas a produção em si foi didática e efetiva, consegui montar e traduzir meu meme e trabalhar com o site facilmente. Foi uma ótima forma de aprendizagem $e$ treino (Vitória).

Eu gostei bastante, porque os memes são uma coisa da internet atual e eu gosto bastante, e acho muito bom a criatividade q algumas pessoas têm em fazê-los. Mas tive um pouco de dificuldade na questão da criatividade das frases (Allan) 


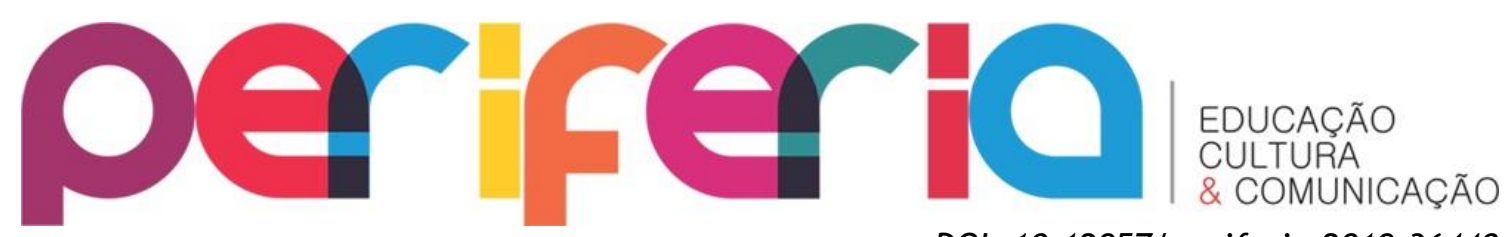

DOI: $10.12957 /$ periferia. 2019.36440

Escrever em inglês foi difícil, porém com a ajuda da professora e do material utilizado consegui fazer as atividades propostas (Joyce)

Após a oficina passei a analisar mais os memes. Tive dificuldades com questão do idioma visto que tenho muita dificuldade em desenvolver em inglês. (João)

Achei interessante a idéia dos professores, principalmente por conseguir inserir na sala de aula um conteúdo que estamos sempre em contato nas redes sociais, tornando a aula diferente e curiosa para os alunos. Ao mesmo tempo que nos divertimos associando as imagens as frases que escrevemos, tivemos que pensar $e$ desenvolver nossa escrita em inglês o que algumas vezes surgia dúvidas. (Hillary)

I loved participate, I love memes and I had no difficulties.(Beatriz)

Foi muito bom, algo que eu só via, mas não sabia fazer (Lana)

Eu adorei a experiência de criar os memes, uma publicação tão legal e muito famosa hoje em dia, tive dificuldades na hora de passar para a língua inglesa já que não sou fluente. Tive bastante dificuldade também na hora de postar o meme no meu perfil. Tirando isso eu adorei.

No entanto, os alunos também demonstraram suas dificuldades relacionadas ao uso das ferramentas digitais, do uso da língua inglesa e de serem críticos ao se posicionarem sobre os assuntos.

Levando-se em consideração a perspectiva de letramentos e, mais especificamente, letramentos digitais, podemos perceber que a sequência didática proporcionou o engajamento dos alunos a partir de um gênero textual próximo ao seu contexto cotidiano. Retomando os dados do PNAD e do questionário em sala, essa faixa etária está entre as que mais estão ativas na internet, fazendo uso muito frequente de redes sociais e acesso à diversas plataformas online. 0 trabalho com gêneros digitais como os memes proporciona e desperta o interesse dos alunos sobre algo que lhes diz respeito e está intrinsecamente ligado às suas comunidades e práticas locais. 0 uso de mídias digitais e a produção através de dispositivos móveis e de internet 


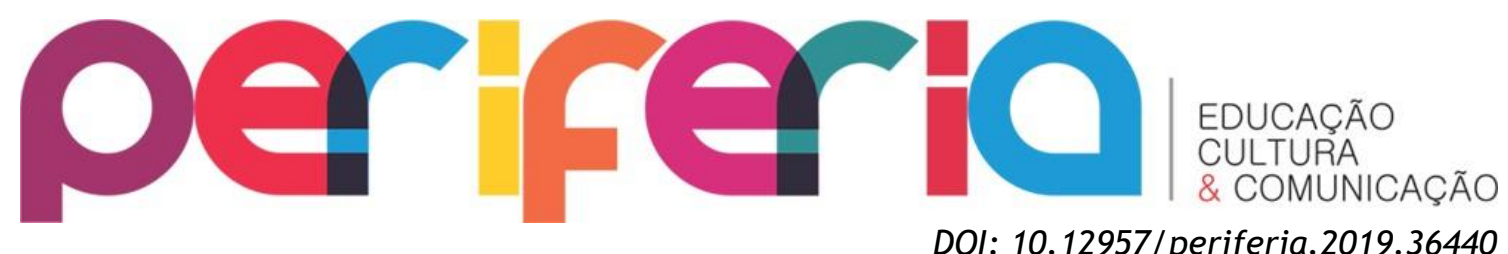

também evidenciam o aspecto semiótico da aplicação das novas tecnologias em práticas pedagógicas inclusivas.

Ainda sendo um gênero híbrido, composto com componentes verbais e imagéticos, o professor tem ainda espaço para problematizar aspectos de multiletramentos, orientando na observação e análise crítica dos elementos que caracterizam o gênero, sobre a dinamicidade de seu uso. Os alunos ainda têm a oportunidade de refletir sobre como esses memes surgiram e podem desaparecer através de um processo histórico de mudança constante de elementos sociais.

\section{CONSIDERAÇÕES FINAIS}

O advento e aplicação de tecnologias por si já promove mudanças nas formas de interação e organização cognitivas humanas desde a invenção da escrita (STREET, 1984). Essas mudanças acabam se refletindo na forma como o conhecimento é passado em nossa sociedade, em particular na instituição definida como transmissora de conhecimento formal: a escola.

Dentro de um contexto globalizante e com a implementação maciça de tecnologias digitais em todos os aspectos da sociedade, cabe uma reflexão sobre o papel do ensino de Língua Inglesa pautado na perspectiva de (multi)letramentos e letramentos digitais (COPE e KALANTZIS, 2000).

0 professor consciente dos mecanismos e dos processos de organização discursivos têm a possibilidade de inverter métodos e técnicas de ensino tradicionais apoiados na transmissão de conhecimento isolado de contexto, que prioriza o conhecimento tecnicista puro. Essa perspectiva é visível em abordagens estruturalistas tão frequentes até hoje no ensino de línguas. 0 foco na estrutura gramatical, na aplicação de regras normativas e de materiais prescritivistas engessa o processo de aprendizagem, gerando baixas expectativas de engajamento e produtividade.

A aplicação de abordagens estruturalistas é ainda reflexo de uma formação inicial de professores que não promove a reflexão crítica sobre o papel de todos os agentes envolvidos no processo de ensino/aprendizagem. 


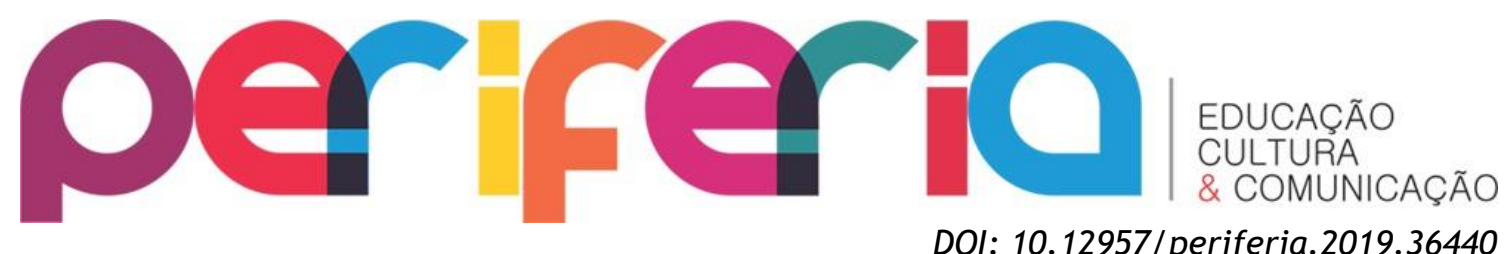

Nesse sentido, o objetivo deste artigo foi evidenciar, através de uma sequência didática baseada em memes, o papel de uma perspectiva crítica do ensino de Língua Inglesa para a promoção da autonomia dos alunos, articulando o conhecimento linguístico com outros saberes.

\section{REFERÊNCIAS}

BAKHTIN, Mikhail. Os gêneros do discurso. In: . Estética da criação verbal. Tradução de Paulo Bezerra. São Paulo: Martins Fontes, 2010.

BLACKMORE, S. The meme machine. Oxford: Oxford University Press, 1999.

CANAGARAJAH, Suresh. Interrogating the "Native Speaker Fallacy": NonLinguistic Roots, Non-Pedagogical Results. In: WILLIAMS, C. (Ed.). Non-native educators in English language teaching. Mahwah, N. J.: Eribaum Associated, 1999b. p. 77- 92.

- Changing Communicative Needs, Revised Assessment Objectives: Testing English as an International Language. Language Assessment Quarterly, v. 3, n.3, p. 229-242, 2006.

In Search of a New Paradigm for Teaching English as an International Language. TESOL Journal, v. 5, n. 4, p. 767-785, December, 2014.

FREIRE, Paulo. Pedagogia do Oprimido. São Paulo: Paz e Terra, 1996.

IBGE. Pesquisa Nacional por Amostra de Domicílios - PNAD. 2016 Disponível em:

https://www.ibge.gov.br/estatisticas-novoportal/sociais/populacao/9127pesquisa-nacional-por-amostra-de-domicilios.html?edicao $=10500 \& \mathrm{t}=$ resultados Acesso em 31/07/2018.

KLEIMAN, Angela. Processo identitários na formação profissional: o professor como agente de letramento. In: CORRÊA, Manoel L. G.; BOCH, Françoise (orgs.). Ensino de língua: representação e letramento. Campinas: Mercado de Letras, 2006, pp.75-91.

MARCONDES, Valéria. Internet, democracia e participação popular: Discutindo experiências participativas. Tese de Doutorado. Faculdade de Comunicação Social, PUCRS. Porto Alegre, 2011, $233 \mathrm{f}$.

PENNYCOOK, Alastair. Uma linguística aplicada transgressiva. In: LOPES, Luiz Paulo da M. (org. ). Por uma linguística indisciplinar. São Paulo: Parábola, 2006, pp. 67-84. 


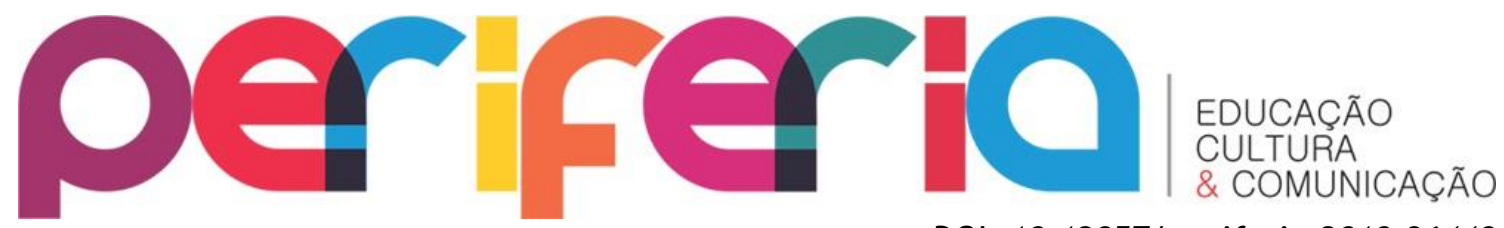

DOI: 10.12957/periferia.2019.36440

RAJAGOPALAN, Kanavillil. 2003. Por uma linguística crítica: linguagem, identidade e a questão ética. São Paulo: Parábola.

ROJO, Roxane; MOURA, Eduardo. Multiletramentos na escola. São Paulo: Parábola, 2012.

STREET, Brian. Literacy in Theory and Practice. Cambridge: Cambridge University Press, 1984. 